\title{
Efficacy of Holmium Laser Enucleation of the Prostate Based on Patient Preoperative Characteristics
}

\author{
Hyun Soo Ryoo ${ }^{1}$, Yoon Seok Suh', Tae Heon Kim¹, Hyun Hwan Sung', Jeongyun Jeong ${ }^{2}$, Kyu-Sung Lee ${ }^{1,3}$ \\ ${ }^{1}$ Department of Urology, Samsung Medical Center, Sungkyunkwan University School of Medicine, Seoul, Korea \\ ${ }^{2}$ Center for Health Promotion, Samsung Medical Center, Seoul, Korea \\ ${ }^{3}$ Department of Medical Device Management and Research, Samsung Advanced Institute for Health Sciences and Technology, Sungkyunkwan University \\ School of Medicine, Seoul, Korea
}

Purpose: To evaluate the efficacy of holmium laser enucleation of the prostate (HoLEP) in relation to prostate size and urodynamic parameters, including bladder outlet obstruction index (BOOI), presence of detrusor overactivity, and detrusor contractility, and to investigate factors predictive of HoLEP success.

Methods: This retrospective analysis of prospective data included 174 consecutive patients treated with HoLEP at Samsung Medical Center from 2009 to 2013. Prostate-specific antigen, prostate size, urodynamic parameters, and International Prostate Symptom Score (IPSS)/quality of life (QoL) were evaluated preoperatively, while prostate-specific antigen, uroflowmetry/postvoid residual (PVR) urine, and IPSS were measured six months after HoLEP. Two definitions of treatment success were established based on the following three variables: IPSS, maximum flow rate (Qmax), and QoL index. Factors predictive of HoLEP success were identified using multiple logistic regression analysis.

Results: IPSS/QoL, Qmax, and PVR improved significantly following HoLEP. Improvements in IPSS and PVR were more significant in the $\mathrm{BOOI} \geq 40$ group compared to the $\mathrm{BOOI}<40$ group, with overall success rates of $93.7 \%$ and $73.6 \%$, respectively. Thus, the $\mathrm{BOOI} \geq 40$ group had a significantly higher success rate, and $\mathrm{BOOI} \geq 40$ was a significant predictor of HoLEP success based on the multivariate analyses.

Conclusions: We found good surgical outcomes after HoLEP, and specifically patients with a higher BOOI had a greater chance of surgical success.

Keywords: Holmium; Lasers; Prostatic Hyperplasia; Urinary Bladder Neck Obstruction; Urinary Bladder, Overactive

- Ethics Research: This study was approved by the Institutional Review Board of Samsung Medical Center (SMC IRB No.: 2011-06-082).

- Conflict of Interest: No potential conflict of interest relevant to this article was reported.

\section{INTRODUCTION}

Since holmium laser enucleation of the prostate (HoLEP) was first described in 1995, it has gained popularity [1-5] such that it is now considered one of the standard treatments for relief of benign prostatic obstructions [3,5-7]. Consequently, there are many studies regarding the efficacy of HoLEP, as well as those comparing HoLEP to other treatment modalities for benign prostatic hyperplasia $(\mathrm{BPH})$ (e.g., transurethral resection of the prostate [TUR-P]) [4,7-10]. However, the efficacy of HoLEP based on patient preoperative characteristics including urodynamic parameters have not been evaluated. Therefore, using

This is an Open Access article distributed under the terms of the Creative Commons Attri(c) (1) \$ bution Non-Commercial License (http://creativecommons.org/licenses/ (c) ${ }_{\mathrm{BY}} \mathrm{NC}$ by-nc/3.0/) which permits unrestricted non-commercial use, distribution, and reproduction in any medium, provided the original work is properly cited.
Corresponding author: Kyu-Sung Lee (iD http://orcid.org/0000-0003-0891-2488 Department of Urology, Samsung Medical Center, Sungkyunkwan University School of Medicine, 81 Irwon-ro, Gangnam-gu, Seoul 06351, Korea E-mail: ksleedr@skku.edu / Tel: +82-2-3410-3554 / Fax: +82-2-3410-3027 ·Hyun Soo Ryoo (D) http://orcid.org/0000-0001-6707-6833

Submitted: July 10, 2015 / Accepted after revision: August 19, 2015 
previous research and, more specifically, the study by Homma et al. [11], we evaluated the success rate of HoLEP, considering preoperative factors including prostate size, the bladder outlet obstruction index (BOOI), presence of detrusor overactivity (DO), and detrusor contractility. Finally, we evaluated factors predictive of HoLEP success.

\section{MATERIALS AND METHODS}

\section{Patients}

This study was approved by the Institutional Review Board of Samsung Medical Center (SMC IRB No.: 2011-06-082). A total of 265 consecutive patients underwent HoLEP for BPH from 2009 to 2013 at Samsung Medical Center. After excluding patients with underlying neurologic disorders or other urologic diseases, such as urinary calculi, urethral stricture, or prostate cancer, 174 patients who were followed-up for at least six months after surgery were enrolled in the final analysis.

\section{Study Design}

All patients underwent clinical evaluations preoperatively and at six months postoperatively. The preoperative evaluations included measurements of the International Prostate Symptom Score (IPSS) and the quality of life (QoL), uroflowmetry, postvoid residual (PVR) urine, urodynamic study (UDS), serum prostatespecific antigen (PSA), and transrectal ultrasonography. UDS was performed according to the recommendations of the International Continence Society [12]. Urodynamic values, such as maximum flow rate (Qmax) and detrusor pressure at Qmax (PdetQ$\max$ ) were recorded. With these parameters, we calculated the bladder outlet obstruction index (BOOI $=$ PdetQmax $-2 \mathrm{Qmax})$ and the bladder contractility index $(\mathrm{BCI}=\mathrm{PdetQmax}+5 \mathrm{Qmax})$ $[13,14]$. Based on the BOOI, the benign prostatic hyperplasia in patients was categorized as obstructed $(\geq 40)$ or unobstructed $(<40)$. We divided patients according to bladder contractility based on the $\mathrm{BCI}$ into normal $(\mathrm{BCI} \geq 100)$ or weak $(\mathrm{BCI}<100)$ $[13,14]$. DO is an urodynamic variable characterized by involuntary detrusor contractions during the filling phase.

Surgical outcomes were analyzed based on the prostate size ( $<40 \mathrm{~mL}, 40-80 \mathrm{~mL},>80 \mathrm{~mL}$ ), BOOI $(<40, \geq 40)$, DO (present or absent), and BCI $(<100, \geq 100)$ values. We evaluated IPSS, QoL, Qmax, and PVR six months after HoLEP and compared the changes in each group.

The definition of treatment success was based on the criteria developed by Homma et al. [11], who presented a table with four domain symptoms, function, anatomy, and QoL, which constitute the efficacy of treatment standards. The domains were evaluated with four variables, IPSS, Qmax, prostate volume, and the QoL index. Overall efficacy was defined as the median efficacy grades from the symptoms, function, and QoL domains. Efficacy grades (excellent, good, fair, and poor) for each domain are summarized in Table 1.

Table 1. Criteria for determining the efficacy of individual domains (symptoms, QoL, and function) and proportion of patients for each efficacy grade

\begin{tabular}{|c|c|c|c|c|}
\hline Efficacy & Post/pre ratio of IPSS & Pre-post of QoL index & Post-pre of Qmax (mL/sec) & No. of patients \\
\hline \multicolumn{5}{|l|}{ Symptom } \\
\hline Excellent & $\leq 0.25$ & & & $85 / 174(48.85)$ \\
\hline Good & $\leq 0.50$ & & & $59 / 174(33.91)$ \\
\hline Fair & $\leq 0.75$ & & & $18 / 174(10.34)$ \\
\hline Poor & $>0.75$ & & & $12 / 174(6.90)$ \\
\hline \multicolumn{5}{|l|}{ QoL } \\
\hline Excellent & & $\geq 4$ & & $51 / 174(29.31)$ \\
\hline Good & & 3 & & $41 / 174(23.56)$ \\
\hline Fair & & 2,1 & & $64 / 174(36.78)$ \\
\hline Poor & & $\leq 0$ & & $18 / 174(10.34)$ \\
\hline \multicolumn{5}{|l|}{ Function } \\
\hline Excellent & & & $\geq 10$ & $99 / 174(56.90)$ \\
\hline Good & & & $\geq 5$ & $29 / 174(16.67)$ \\
\hline Fair & & & $\geq 2.5$ & $21 / 174(12.07)$ \\
\hline Poor & & & $<2.5$ & $25 / 174(14.37)$ \\
\hline
\end{tabular}

Overall efficacy is the median of efficacy grades of 3 domains.

QoL, quality of life; Qmax, maximum flow rate. 
In our study, treatment was considered successful if the overall efficacy demonstrated an improvement that was "fair or greater" (definition 1) and "good or greater" (definition 2).

A multiple logistic regression analysis was used to identify predictive factors for the success of HoLEP. Age, PSA, IPSS, QoL, Qmax, PVR, prostate size, BOOI, BCI, PdetQmax, and DO were included in our analyses.

\section{Statistical Analyses}

Statistical analyses were performed with the IBM SPSS Statistics ver. 20.0 (IBM Co., Armonk, NY, USA). The independent t-test was used to compare the improvement in differences between the two score groups for each of the following measurements: BOOI, DO, and BCI. A one-way analysis of variance (ANOVA) was used to compare the improvement in differences among the three score groups analyzed according to prostate size. If factors that were significantly different among the three groups were present, the post hoc Tukey test was used to determine which specific groups were driving the differences. The chi-square test was used to compare success rates between the groups analyzed according to prostate size, $\mathrm{BOOI}, \mathrm{DO}$, and $\mathrm{BCI}$. Multiple logistic regression models identified factors predictive of HoLEP success. In order to derive a final model of independently significant variables predicting success of HoLEP, all variables with a P-value $<0.20$ on univariate analyses were incorporated into the multivariate analyses. A P-value $<0.05$ was considered significant.

\section{RESULTS}

\section{Patient Dispositions, Baseline Characteristics, and Operative Parameters}

The mean age of patients evaluated was 69.3 years (range, 5288 years). Table 2 shows preoperative patient characteristics. Mean prostate size, BOOI, and BCI were $66.2 \pm 34.3 \mathrm{~mL}$, $57.9 \pm 29.2$, and $111.8 \pm 33.1$, respectively. Ninety-two patients were diagnosed with DO. Preoperative baseline PSA was significantly higher in the following groups: $\mathrm{BOOI} \geq 40, \mathrm{BCI} \geq 100$, and prostate size $>80 \mathrm{~mL}(\mathrm{P}=0.015, \mathrm{P}=0.021$ [independent $\mathrm{t}$ test], and $\mathrm{P}<0.001$ [one-way ANOVA], respectively). Preoperative Qmax was significantly lower $(\mathrm{P}=0.029)$ and $\mathrm{PVR}$ was significantly higher $(\mathrm{P}=0.011)$ in the $\mathrm{BOOI} \geq 40$ group compared to the other groups. The mean total operative, enucleation, and morcellation times were $78.53 \pm 43.48,49.21 \pm 25.12$, and $14.56 \pm 16.45$ minutes, respectively. The duration of postoperative indwelling catheter and hospitalization were $1.79 \pm 1.00$ and $3.92 \pm 1.31$ days, respectively.

\section{Improvement of Parameters Following HoLEP}

Six months after undergoing HoLEP, all parameters showed significant improvement. Fig. 1 shows changes in the parameter values. The mean total IPSS score decreased significantly from $21.7 \pm 6.6$ to $6.8 \pm 5.2$; the QoL score also decreased significantly (from $4.5 \pm 2.4$ to $1.7 \pm 1.3$ ). The mean values of $\mathrm{Qmax}$ (from $8.7 \pm 3.8$ to

Table 2. Preoperative baseline characteristics

\begin{tabular}{|c|c|c|c|c|c|c|}
\hline Characteristic & Age (yr) & PSA (ng/mL) & IPSS & QoL & $\mathrm{Qmax}(\mathrm{mL} / \mathrm{sec})$ & PVR (mL) \\
\hline Patients $(\mathrm{n}=174)$ & $69.3 \pm 7.1$ & $5.0 \pm 6.8$ & $21.7 \pm 6.6$ & $4.5 \pm 2.4$ & $8.7 \pm 3.8$ & $107.7 \pm 111.0$ \\
\hline $\begin{array}{l}\text { Prostate size }(\mathrm{mL}) \\
\quad<40(\mathrm{n}=27) \\
40-80(\mathrm{n}=107) \\
>80(\mathrm{n}=40)\end{array}$ & $\begin{array}{l}67.0 \pm 6.3 \\
69.0 \pm 7.0 \\
71.7 \pm 7.2\end{array}$ & $\begin{array}{c}1.3 \pm 1.1 \\
3.7 \pm 3.1 \\
11.1 \pm 11.3^{*}\end{array}$ & $\begin{array}{l}23.0 \pm 7.7 \\
21.1 \pm 6.4 \\
22.4 \pm 6.6\end{array}$ & $\begin{array}{l}4.5 \pm 0.9 \\
4.3 \pm 1.0 \\
5.1 \pm 4.8\end{array}$ & $\begin{array}{l}9.2 \pm 4.0 \\
8.7 \pm 3.7 \\
8.3 \pm 3.8\end{array}$ & $\begin{array}{l}113.1 \pm 120.6 \\
107.4 \pm 117.7 \\
105.0 \pm 85.7\end{array}$ \\
\hline $\begin{array}{l}\text { BOOI } \\
\qquad<40(\mathrm{n}=57) \\
\quad \geq 40(\mathrm{n}=117)\end{array}$ & $\begin{array}{l}69.3 \pm 5.3 \\
69.3 \pm 7.8\end{array}$ & $\begin{array}{l}3.2 \pm 3.1 \\
5.9 \pm 7.9^{*}\end{array}$ & $\begin{array}{l}21.2 \pm 7.6 \\
21.9 \pm 6.2\end{array}$ & $\begin{array}{l}4.4 \pm 0.9 \\
4.6 \pm 2.9\end{array}$ & $\begin{array}{l}9.6 \pm 3.7^{*} \\
8.3 \pm 3.7\end{array}$ & $\begin{array}{c}77.2 \pm 62.4 \\
122.6 \pm 125.8^{*}\end{array}$ \\
\hline $\begin{array}{l}\text { DO } \\
\qquad \begin{array}{l}\text { Yes }(n=92) \\
\text { No }(n=82)\end{array}\end{array}$ & $\begin{array}{l}71.1 \pm 6.9 \\
67.2 \pm 6.7\end{array}$ & $\begin{array}{l}5.5 \pm 6.9 \\
4.4 \pm 6.8\end{array}$ & $\begin{array}{l}22.2 \pm 6.9 \\
21.1 \pm 6.4\end{array}$ & $\begin{array}{l}4.8 \pm 3.3 \\
4.3 \pm 1.0\end{array}$ & $\begin{array}{l}8.4 \pm 3.8 \\
9.0 \pm 3.7\end{array}$ & $\begin{array}{l}100.7 \pm 83.6 \\
115.7 \pm 135.5\end{array}$ \\
\hline $\begin{array}{l}\text { BCI } \\
\quad<100(\mathrm{n}=71) \\
\quad \geq 100(\mathrm{n}=103)\end{array}$ & $\begin{array}{l}69.2 \pm 6.2 \\
69.3 \pm 7.7\end{array}$ & $\begin{array}{l}3.6 \pm 4.6 \\
6.0 \pm 7.9^{*}\end{array}$ & $\begin{array}{l}21.9 \pm 6.7 \\
21.6 \pm 6.6\end{array}$ & $\begin{array}{l}4.3 \pm 0.9 \\
4.7 \pm 3.1\end{array}$ & $\begin{array}{l}8.0 \pm 3.3 \\
9.2 \pm 4.0\end{array}$ & $\begin{array}{l}116.9 \pm 121.3 \\
101.4 \pm 103.5\end{array}$ \\
\hline
\end{tabular}

Values are presented as mean \pm standard deviation.

PSA, prostate-specific antigen; IPSS, International Prostate Symptom Score; QoL, quality of life; Qmax, maximum flow rate; PVR, postvoid residual; BOOI, bladder outlet obstruction index; DO, detrusor overactivity; BCI, bladder contractility index.

${ }^{*} \mathrm{P}<0.05$, compare preoperative values between groups according to prostate size, $\mathrm{BOOI}, \mathrm{DO}$, and $\mathrm{BCI}$. 
$24.1 \pm 35.1$ ) and PVR (from 107.7 \pm 111.0 to $25.6 \pm 24.3$ ) improved significantly $(\mathrm{P}<0.05$ for each).

Table 3 shows the postoperative changes in the parameter values for prostate size, BOOI, DO, and BCI values. No significant differences were observed in the postoperative improvement of prostate size, DO, or BCI. IPSS and PVR values significantly improved in the $\mathrm{BOOI} \geq 40$ group than in the $\mathrm{BOOI}<40$ group. On the contrary, there were no significant changes in QoL and Qmax based on the BOOI.

\section{HoLEP Success Rate}

Efficacy grades and proportions of patients for each efficacy grade are summarized in Table 1 . Of the 174 patients, treatment in 163 patients (93.7\%) was deemed successful based on success definition 1, while the overall success rate according to success definition 2 was $73.6 \%$.

Table 4 shows success rates based on prostate size, BOOI, DO, and BCI values satisfying definitions 1 and 2 . The success rate was significantly higher in the $\mathrm{BOOI} \geq 40$ group than in the

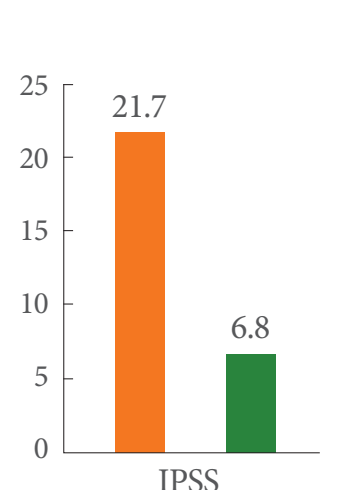

IPSS
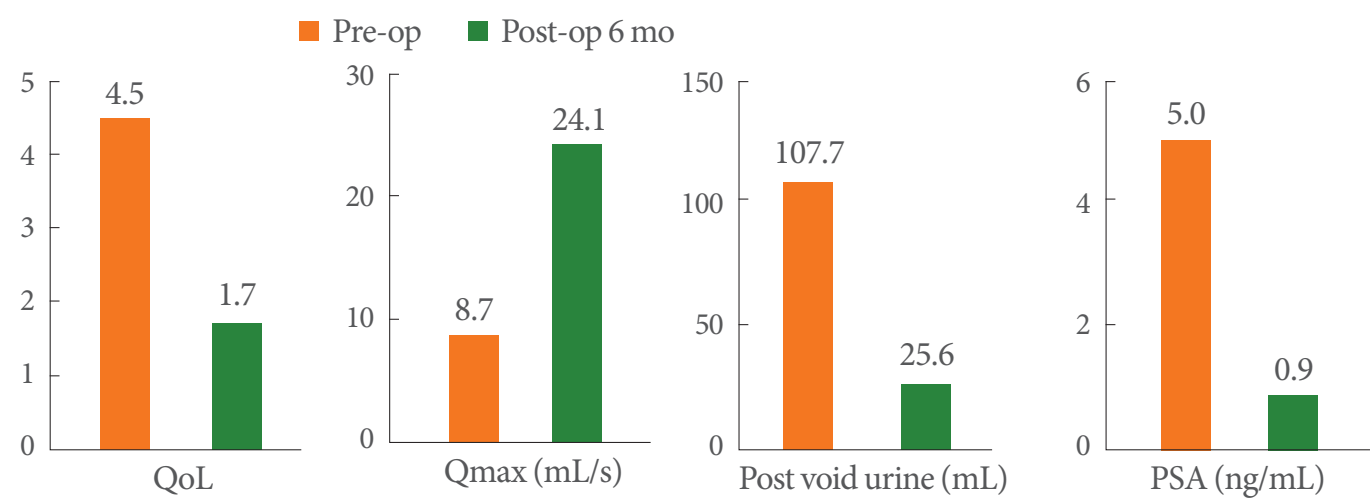

Fig. 1. Changes in preoperative and postoperative six months values. The mean total International Prostate Symptom Score (IPSS) score for all patients decreases significantly from $21.7 \pm 6.6$ to $6.8 \pm 5.2$; the quality of life (QoL) score also decreases (4.5 \pm 2.4 to $1.7 \pm 1.3)$. Meanwhile, the mean values of maximum flow rate (Qmax) (8.7 \pm 3.8 to $24.1 \pm 35.1)$ and postvoid residual urine (PVR) (107.7 \pm 111.0 to $25.6 \pm 24.3)$ improve significantly $(\mathrm{P}<0.05$ for each).

Table 3. Change in parameters preoperatively and six months postoperatively according to prostate size, BOOI, DO, and BCI values

\begin{tabular}{|c|c|c|c|c|c|c|c|c|c|}
\hline \multirow{2}{*}{ Parameter } & \multicolumn{3}{|c|}{ Prostate size $(\mathrm{mL})$} & \multicolumn{2}{|c|}{ BOOI } & \multicolumn{2}{|c|}{$\mathrm{DO}$} & \multicolumn{2}{|c|}{$\mathrm{BCI}$} \\
\hline & $<40(\mathrm{n}=27)$ & $40-80(n=107)$ & $>80(\mathrm{n}=40)$ & $<40(\mathrm{n}=57)$ & $\geq 40(n=117)$ & Yes $(n=92)$ & No $(n=82)$ & $<100(\mathrm{n}=71)$ & $\geq 100(n=103)$ \\
\hline \multicolumn{10}{|l|}{ IPSS } \\
\hline Pre-op & $23.0 \pm 7.7$ & $21.1 \pm 6.4$ & $22.4 \pm 6.6$ & $21.2 \pm 7.6$ & $21.9 \pm 6.2$ & $22.2 \pm 6.9$ & $21.1 \pm 6.4$ & $21.9 \pm 6.7$ & $21.6 \pm 6.6$ \\
\hline Post-op & $8.3 \pm 5.2$ & $6.3 \pm 4.9$ & $6.9 \pm 5.8$ & $8.4 \pm 6.0$ & $6.0 \pm 4.5$ & $6.5 \pm 5.3$ & $7.1 \pm 5.0$ & $7.7 \pm 5.5$ & $6.1 \pm 4.8$ \\
\hline Changes & $-14.7 \pm 8.1$ & $-14.8 \pm 7.2$ & $-15.5 \pm 7.8$ & $-12.8 \pm 9.0^{\star}$ & $-15.9 \pm 6.4^{\star}$ & $-15.7 \pm 7.6$ & $-14.0 \pm 7.3$ & $-14.2 \pm 7.8$ & $-15.5 \pm 7.2$ \\
\hline \multicolumn{10}{|l|}{ QoL } \\
\hline Pre-op & $4.5 \pm 0.9$ & $4.3 \pm 1.0$ & $5.1 \pm 4.8$ & $4.4 \pm 0.9$ & $4.6 \pm 2.9$ & $4.8 \pm 3.3$ & $4.3 \pm 1.0$ & $4.3 \pm 0.9$ & $4.7 \pm 3.1$ \\
\hline Post-op & $2.0 \pm 1.4$ & $1.7 \pm 1.3$ & $1.7 \pm 1.4$ & $2.1 \pm 1.3$ & $1.6 \pm 1.3$ & $1.6 \pm 1.5$ & $1.9 \pm 1.2$ & $2.0 \pm 1.3$ & $1.6 \pm 1.3$ \\
\hline Changes & $-2.5 \pm 1.5$ & $-2.6 \pm 1.6$ & $-3.4 \pm 4.9$ & $-2.4 \pm 1.5$ & $-3.0 \pm 3.1$ & $-3.1 \pm 3.4$ & $-2.4 \pm 1.5$ & $-2.3 \pm 1.6$ & $-3.1 \pm 3.2$ \\
\hline \multicolumn{10}{|c|}{$\mathrm{Qmax}(\mathrm{mL} / \mathrm{sec})$} \\
\hline Pre-op & $9.2 \pm 4.0$ & $8.7 \pm 3.7$ & $8.3 \pm 3.8$ & $9.6 \pm 3.7$ & $8.3 \pm 3.7$ & $8.4 \pm 3.8$ & $9.0 \pm 3.7$ & $8.0 \pm 3.3$ & $9.2 \pm 4.0$ \\
\hline Post-op & $18.2 \pm 8.1$ & $26.1 \pm 44.2$ & $22.9 \pm 8.6$ & $20.1 \pm 9.0$ & $26.1 \pm 42.3$ & $22.4 \pm 15.7$ & $26.0 \pm 48.5$ & $19.5 \pm 8.4$ & $27.3 \pm 45.0$ \\
\hline Changes & $9.0 \pm 7.5$ & $17.3 \pm 43.6$ & $14.6 \pm 9.2$ & $10.5 \pm 8.5$ & $17.8 \pm 41.7$ & $14.0 \pm 15.2$ & $17.0 \pm 47.9$ & $11.5 \pm 8.4$ & $18.1 \pm 44.4$ \\
\hline \multicolumn{10}{|l|}{$\operatorname{PVR}(\mathrm{mL})$} \\
\hline Pre-op & $113.1 \pm 120.6$ & $107.4 \pm 117.7$ & $105.0 \pm 85.7$ & $77.2 \pm 62.4$ & $122.6 \pm 125.8$ & $100.7 \pm 83.6$ & $115.7 \pm 135.5$ & $116.9 \pm 121.3$ & $101.4 \pm 103.5$ \\
\hline Post-op & $27.1 \pm 40.9$ & $25.3 \pm 20.6$ & $25.5 \pm 18.6$ & $19.6 \pm 17.3$ & $28.5 \pm 26.6$ & $25.0 \pm 19.3$ & $26.2 \pm 29.0$ & $24.5 \pm 26.8$ & $26.3 \pm 22.5$ \\
\hline Changes & $-86.0 \pm 90.5$ & $-82.1 \pm 112.7$ & $-79.6 \pm 85.8$ & $-57.6 \pm 63.7^{\star}$ & $-94.1 \pm 116.3^{*}$ & $-75.7 \pm 85.7$ & $-89.4 \pm 120.3$ & $-92.3 \pm 108.5$ & $-75.1 \pm 99.6$ \\
\hline
\end{tabular}

Values are presented as mean \pm standard deviation.

BOOI, bladder outlet obstruction index; DO, detrusor overactivity; BCI, bladder contractility index; PSA, prostate-specific antigen; IPSS, International Prostate Symptom Score; QoL, quality of life; Qmax, maximum flow rate; PVR, postvoid residual.

${ }^{*} \mathrm{P}<0.05$; compare improvements between groups according to prostate size, BOOI, DO, BCI. 
Table 4. Success rates according to definitions 1 and 2 according to prostate size, BOOI, DO, and BCI values

\begin{tabular}{|c|c|c|c|c|c|c|c|c|c|c|}
\hline \multirow{2}{*}{ Success rate } & \multirow{2}{*}{ All patients } & \multicolumn{3}{|c|}{ Prostate size $(\mathrm{mL})$} & \multicolumn{2}{|c|}{ BOOI } & \multicolumn{2}{|c|}{ DO } & \multicolumn{2}{|c|}{ BCI } \\
\hline & & $<40$ & $40-80$ & $>80$ & $<40$ & $\geq 40$ & Yes & No & $<100$ & $\geq 100$ \\
\hline \multicolumn{11}{|l|}{ Definition $1^{\text {a) }}$} \\
\hline Rates (\%) & 93.7 & 96.3 & 93.5 & 92.5 & 84.2 & 98.3 & 93.5 & 93.9 & 91.5 & 95.1 \\
\hline P-value & & & 0.813 & & \multicolumn{2}{|c|}{$<0.001$} & \multicolumn{2}{|c|}{0.359} & \multicolumn{2}{|c|}{0.909} \\
\hline \multicolumn{11}{|l|}{ Definition $2^{\text {b) }}$} \\
\hline Rates (\%) & 73.6 & 77.8 & 72.9 & 72.5 & 61.4 & 79.5 & 76.1 & 70.7 & 70.4 & 75.7 \\
\hline P-value & & \multicolumn{3}{|c|}{0.863} & \multicolumn{2}{|c|}{0.032} & \multicolumn{2}{|c|}{0.424} & \multicolumn{2}{|c|}{0.435} \\
\hline
\end{tabular}

BOOI, bladder outlet obstruction index; DO, detrusor overactivity; BCI, bladder contractility index.

a) Success definition 1: The overall efficacy demonstrates an improvement that was "fair or greater". ${ }^{\text {b) }}$ Success definition 2: The overall efficacy demonstrates an improvement that was "good or greater".

Table 5. Multiple logistic regression analysis of factors influencing holmium laser enucleation of the prostate success at 6 months postoperatively

\begin{tabular}{|c|c|c|c|c|c|c|c|c|}
\hline \multirow{3}{*}{ Variable } & \multicolumn{4}{|c|}{ Success definition 1} & \multicolumn{4}{|c|}{ Success definition 2} \\
\hline & \multicolumn{2}{|c|}{ Univariable analysis } & \multicolumn{2}{|c|}{ Multivariable analysis } & \multicolumn{2}{|c|}{ Univariable analysis } & \multicolumn{2}{|c|}{ Multivariable analysis } \\
\hline & OR (95\% CI) & $\mathrm{P}$-value & OR (95\% CI) & $\mathrm{P}$-value & OR (95\% CI) & $\mathrm{P}$-value & OR (95\% CI) & P-value \\
\hline Age & $1.03(0.95-1.13)$ & 0.450 & & & $1.01(0.96-1.06)$ & 0.676 & & \\
\hline PSA & $1.07(0.91-1.27)$ & 0.424 & & & $1.01(0.96-1.07)$ & 0.634 & & \\
\hline IPSS & $1.04(0.95-1.14)$ & 0.406 & & & $1.00(0.95-1.05)$ & 0.974 & & \\
\hline QoL & $1.10(0.66-1.83)$ & 0.719 & & & $1.10(0.79-1.53)$ & 0.591 & & \\
\hline PVR & $1.00(1.00-1.01)$ & 0.481 & & & $1.00(0.99-1.00)$ & 0.817 & & \\
\hline \multicolumn{9}{|l|}{ Prostate size } \\
\hline$<40$ & \multicolumn{2}{|c|}{ Reference } & & & \multicolumn{2}{|c|}{ Reference } & & \\
\hline $40-80$ & $0.55(0.07-4.67)$ & 0.583 & & & $0.77(0.28-2.09)$ & 0.607 & & \\
\hline$>80$ & $0.47(0.05-4.82)$ & 0.528 & & & $0.75(0.24-2.36)$ & 0.627 & & \\
\hline $\mathrm{BOOI} \geq 40$ & $10.8(2.25-51.76)$ & 0.003 & $14.47(1.22-171.00)$ & 0.034 & $2.44(1.21-4.89)$ & 0.012 & $1.55(0.59-4.11)$ & 0.377 \\
\hline $\mathrm{BCI} \geq 100$ & $1.81(0.53-6.18)$ & 0.344 & & & $1.31(0.66-2.59)$ & 0.436 & & \\
\hline PdetQmax & $1.04(1.00-1.07)$ & 0.031 & $0.99(0.95-1.04)$ & 0.752 & $1.02(1.00-1.03)$ & 0.012 & $1.01(0.99-1.03)$ & 0.215 \\
\hline DO & $0.93(0.27-3.17)$ & 0.909 & & & $1.32(0.67-2.59)$ & 0.425 & & \\
\hline
\end{tabular}

OR, odds ratio; CI, confidence interval; PSA, prostate-specific antigen; IPSS, International Prostate Symptom Score; QoL, quality of life; Qmax, maximum flow rate; PVR, postvoid residual; BOOI, bladder outlet obstruction index; BCI, bladder contractility index; PdetQmax, detrusor pressure at Qmax; DO, detrusor overactivity.

BOOI $<40$ group (98.3\% vs. $84.2 \%$ ) according to definition 1 $(\mathrm{P}<0.001)$. Likewise, success rate in the $\mathrm{BOOI} \geq 40$ group was significantly higher than that in the $\mathrm{BOOI}<40$ group $(79.5 \%$ vs. $61.4 \%)(\mathrm{P}=0.032)$ according to definition 2 . However, no significant differences were observed in success rates between the groups based on prostate size, DO, or BCI values.

\section{Evaluation of Predictors for HoLEP Success}

Among the preoperative variables that were suspected of affecting HoLEP treatment success, BOOI and PdetQmax were found to be independently significant factors that correlated with success definitions 1 and 2 on univariate analyses (Table 5). On multivariate analyses, only BOOI was found to be significantly associated with success definition 1 (odds ratio, 14.47; $95 \%$ confidence interval, 1.22-171.00; $\mathrm{P}=0.034)$. However, no variables were found to be associated with success definition 2 on multivariate analyses.

\section{DISCUSSION}

In the present study, we evaluated the efficacy of HoLEP based on preoperative urodynamic parameters (BOOI, bladder con- 
tractility, DO) and prostate size. Although significant improvements in all parameters were observed, no significant differences were observed in the postoperative parameters with the exception of BOOI between the success and nonsuccess groups. The improvements in IPSS and PVR were significantly higher in the $\mathrm{BOOI} \geq 40$ group than in the $\mathrm{BOOI}<40$ group. The overall success rates were $93.7 \%$ and $73.6 \%$ based on definitions 1 and 2, respectively. The success rate was significantly higher for the BOOI $\geq 40$ group. However, no significant differences were found based on the prostate size, BCI, or DO by definitions 1 and 2. In addition, we identified factors associated with HoLEP success using multiple logistic regression analysis. Degree of BOO and PedtQmax were significantly associated with HoLEP success on univariate analysis, but on multivariate analysis, degree of $\mathrm{BOO}$ was the only significant prognostic factor that was able to satisfy success definition 1 .

Despite our goal of conducting an objective evaluation, consistent criteria for determining success of HoLEP are not yet available. In situations where definite criteria exist, it is possible to compare treatment efficacy objectively on a common scale. Additionally, when we know which factors are related to success, we are more likely to select patients who need treatment. Therefore, criteria for evaluating HoLEP success should be standardized, and factors related to its success should be identified. It is important that not only patients' subjective symptoms (e.g., IPSS/QoL) but also objective indicators (e.g., uroflowmetry) be considered when developing success criteria to accurately evaluate efficacy. Homma et al. [11] established the following four domains for efficacy evaluation criteria: symptoms, function, anatomy, and QoL. They defined overall efficacy as the median efficacy grades from the symptoms, function, and QoL domains. These proposed criteria are fairly accurate and practical. Thus, we utilized them in our assessment of the clinical efficacy of HoLEP. This efficacy grading method proved simple and easy to measure as well as cost effective.

Seki et al. [15] arbitrarily established definitions of treatment success for each variable (IPSS, QoL, and Qmax) using the criteria suggested by Homma et al. [11]. They identified factors related to success for each outcome variable by performing multiple logistic regression analyses. Because the prognostic value of each variable may be affected by the criteria used to estimate the outcome, that study was designed to identify predictive variables using two different definitions in order to minimize any bias arising from the estimation criteria themselves. After reviewing these studies, we established two definitions of treat- ment success, and identified factors related to HoLEP success. Our results indicated that BOOI is an important parameter for predicting HoLEP efficacy.

Prior to our research, to our knowledge, there have been no investigations into the efficacy of HoLEP based on patient characteristics, particularly urodynamic parameters. However, BOO relief is believed to be the primary treatment objective in patients with $\mathrm{BPH}$, and many surgical treatment methods have emerged based on this principle. Among the many surgical options for BPH, TUR-P is one of the most common. Many studies have evaluated the effects of TUR-P based on urodynamic parameters of patients [14,16-18].

In our previous study [14] patients were divided into a detrusor underactivity (DUA) group and $\mathrm{BOO}$ or normal detrusor contractility group according to $\mathrm{BOOI}$ and $\mathrm{BCI}$ values. We investigated the differences in IPSS, QoL, Qmax, and PVR before and after TUR-P between the groups. In this study, the postoperative improvement rates for IPSS were lower in the DUA group than in the other group. However, a different study [17] reported that changes in IPSS, QoL, Qmax, and PVR after TUR-P were not significantly different across the three groups evaluated (urodynamically unobstructed, equivocal, and obstructed). They insisted that TUR-P could be expected to improve LUTS in patients with BPH without definite urodynamic obstruction. Although some studies have suggested that the degree of obstruction does not significantly affect TUR-P efficacy, most indicate that the efficacy of TUR-P improves as the preoperative degree of BOO worsens $[16,18]$. Because HoLEP treats $\mathrm{BPH}$ by relieving $\mathrm{BOO}$ like TUR-P, we expect that the degree of BOO also has an important role in the efficacy of HoLEP, and our study results support this notion.

Although there has been no study investigating predictors of HoLEP success, a few studies have mentioned predictors of TUR-P outcome $[15,19,20]$. Most studies have suggested that the degree of $\mathrm{BOO}$ is a predictor of TUR-P outcome. Few studies have reported that detrusor contractility is also a significant predictor of TUR-P efficacy. Seki et al. [15] reported that the presence of DO was a negative predictor for QoL improvement after TUR-P. Furthermore, other studies $[19,20]$ have reported that not only the degree of BOO, but also detrusor contractility, can reliably predict TUR-P outcome. However, in our study, the multivariate analysis indicated that detrusor contractility was not a significant predictor of HoLEP outcome. A BOOI $\geq 40$ was the only factor significantly associated with HoLEP success. We believe this is the first attempt at examining the relationship 
between urodynamic parameters and HoLEP success.

Our study has some limitations. Before conducting this study, we suspected that HoLEP might be less effective for patients with low $\mathrm{BOOI}$ and $\mathrm{BCI}$ values. Therefore, few patients with these characteristics were chosen to undergo HoLEP treatment (low BOOI, $n=57$; low BCI, $n=71$; both, $n=38$ ). Most of the patients who did not have definite $\mathrm{BOO}$ were enrolled because of their subjective symptoms related to voiding difficulty and large prostatic size on transrectal ultrasonography. However, as suspected, these patients presented a worse outcome. This could have resulted in a selection bias in our study because the patients who were most likely to benefit from HoLEP treatment were those who were selected for treatment; thus, this might be the reason why we observed a significant improvement in the mean values of all parameters examined in this study.

In conclusion, we found that the improvement in IPSS and PVR was significantly higher in the $\mathrm{BOOI} \geq 40$ group than in the $\mathrm{BOOI}<40$ group. No significant between-group differences were observed for any of the parameters postoperatively based on prostate size, DO, or BCI values. Success rate of the $\mathrm{BOOI} \geq 40$ group was significantly higher than that of the $\mathrm{BOOI}<40$ group. According to our multivariate analyses, degree of $\mathrm{BOO}$ is the only factor among several variables that affects the success of HoLEP.

\section{REFERENCES}

1. Cho KJ, Kim HS, Koh JS, Han SB, Kim SH, Kim HW, et al. Preoperative factors affecting postoperative early quality of life during the learning curve of holmium laser enucleation of the prostate. Int Neurourol J 2013;17:83-9.

2. Gilling PJ, Cass CB, Malcolm AR, Fraundorfer MR. Combination holmium and Nd:YAG laser ablation of the prostate: initial clinical experience. J Endourol 1995;9:151-3.

3. Lee MH, Yang HJ, Kim DS, Lee CH, Jeon YS. Holmium laser enucleation of the prostate is effective in the treatment of symptomatic benign prostatic hyperplasia of any size including a small prostate. Korean J Urol 2014;55:737-41.

4. Rocco B, Albo G, Ferreira RC, Spinelli M, Cozzi G, Dellorto P, et al. Recent advances in the surgical treatment of benign prostatic hyperplasia. Ther Adv Urol 2011;3:263-72.

5. Gupta NP, Anand A. Comparison of TURP, TUVRP, and HoLEP. Curr Urol Rep 2009;10:276-8.

6. Elzayat EA, Habib EI, Elhilali MM. Holmium laser enucleation of the prostate: a size-independent new "gold standard". Urology
2005;66(5 Suppl):108-13.

7. Ahyai SA, Gilling P, Kaplan SA, Kuntz RM, Madersbacher S, Montorsi F, et al. Meta-analysis of functional outcomes and complications following transurethral procedures for lower urinary tract symptoms resulting from benign prostatic enlargement. Eur Urol 2010;58:384-97.

8. Fayad AS, Sheikh MG, Zakaria T, Elfottoh HA, Alsergany R. Holmium laser enucleation versus bipolar resection of the prostate: a prospective randomized study. Which to choose? J Endourol 2011;25: $1347-52$.

9. Wilson LC, Gilling PJ, Williams A, Kennett KM, Frampton CM, Westenberg AM, et al. A randomised trial comparing holmium laser enucleation versus transurethral resection in the treatment of prostates larger than 40 grams: results at 2 years. Eur Urol 2006;50:56973.

10. Lee SW, Choi JB, Lee KS, Kim TH, Son H, Jung TY, et al. Transurethral procedures for lower urinary tract symptoms resulting from benign prostatic enlargement: a quality and meta-analysis. Int Neurourol J 2013;17:59-66.

11. Homma Y, Kawabe K, Tsukamoto T, Yamaguchi O, Okada K, Aso Y, et al. Estimate criteria for efficacy of treatment in benign prostatic hyperplasia. Int J Urol 1996;3:267-73.

12. Schäfer W, Abrams P, Liao L, Mattiasson A, Pesce F, Spangberg A, et al. Good urodynamic practices: uroflowmetry, filling cystometry, and pressure-flow studies. Neurourol Urodyn 2002;21:261-74.

13. Abrams P. Bladder outlet obstruction index, bladder contractility index and bladder voiding efficiency: three simple indices to define bladder voiding function. BJU Int 1999;84:14-5.

14. Han DH, Jeong YS, Choo MS, Lee KS. The efficacy of transurethral resection of the prostate in the patients with weak bladder contractility index. Urology 2008;71:657-61.

15. Seki N, Kai N, Seguchi H, Takei M, Yamaguchi A, Naito S. Predictives regarding outcome after transurethral resection for prostatic adenoma associated with detrusor underactivity. Urology 2006;67: 306-10.

16. van Venrooij GE, van Melick HH, Boon TA. Comparison of outcomes of transurethral prostate resection in urodynamicallyobstructed versus selected urodynamicallyunobstructed or equivocal men. Urology 2003;62:672-6.

17. Min DS, Cho HJ, Kang JY, Yoo TK, Cho JM. Effect of transurethral resection of the prostate based on the degree of obstruction seen in urodynamic study. Korean J Urol 2013;54:840-5.

18. Tanaka Y, Masumori N, Itoh N, Furuya S, Ogura H, Tsukamoto T. Is the short-term outcome of transurethral resection of the prostate affected by preoperative degree of bladder outlet obstruction, status 
of detrusor contractility or detrusor overactivity? Int J Urol 2006; 13:1398-404.

19. Machino R, Kakizaki H, Ameda K, Shibata T, Tanaka H, Matsuura $S$, et al. Detrusor instability with equivocal obstruction: A predictor of unfavorable symptomatic outcomes after transurethral prosta- tectomy. Neurourol Urodyn 2002;21:444-9.

20. Javle P, Jenkins SA, Machin DG, Parsons KF. Grading of benign prostatic obstruction can predict the outcome of transurethral prostatectomy. J Urol 1998;160:1713-7. 